\title{
Phosphorylation of mammalian Sgo2 by Aurora B recruits PP2A and MCAK to centromeres
}

\author{
Yuji Tanno, ${ }^{1,2}$ Tomoya S. Kitajima, ${ }^{1,3}$ Takashi Honda, ${ }^{1,2}$ Yasuto Ando, ${ }^{1,2}$ Kei-ichiro Ishiguro, ${ }^{1}$ \\ and Yoshinori Watanabe ${ }^{1,2,4}$ \\ ${ }^{1}$ Laboratory of Chromosome Dynamics, Institute of Molecular and Cellular Biosciences, University of Tokyo, Yayoi, Tokyo \\ 113-0032, Japan; ${ }^{2}$ Graduate School of Agricultural and life Science, University of Tokyo, Yayoi, Tokyo 113-0032, Japan
}

\begin{abstract}
Shugoshin (Sgo) is a conserved centromeric protein. Mammalian Sgo1 collaborates with protein phosphatase 2A (PP2A) to protect mitotic cohesin from the prophase dissociation pathway. Although another shugoshin-like protein, Sgo2, is required for the centromeric protection of cohesion in germ cells, its precise molecular function remains largely elusive. We demonstrate that hSgo2 plays a dual role in chromosome congression and centromeric protection of cohesion in HeLa cells, while the latter function is exposed only in perturbed mitosis. These functions partly overlap with those of Aurora B, a kinase setting faithful chromosome segregation. Accordingly, we identified the phosphorylation of hSgo 2 by Aurora $B$ at the $\mathrm{N}$-terminal coiled-coil region and the middle region, and showed that these phosphorylations separately promote binding of hSgo2 to PP2A and MCAK, factors required for centromeric protection and chromosome congression, respectively. Furthermore, these phosphorylations are essential for localizing PP2A and MCAK to centromeres. This mechanism seems applicable to germ cells as well. Thus, our study identifies Sgo2 as a hitherto unknown crucial cellular substrate of Aurora B in mammalian cells.
\end{abstract}

[Keywords: Chromosome segregation; centromere; shugoshin; Aurora B; MCAK; PP2A]

Supplemental material is available at http://www.genesdev.org.

Received May 6, 2010; revised version accepted August 10, 2010.

Chromosomal instability, commonly associated with human cancers, may arise from the failure of accurate chromosome segregation in mitosis. To prevent this failure, several mechanisms function by ensuring that the kinetochores of sister chromatids are properly attached to spindle microtubules. Within the cell cycle, sister chromatid cohesion is established during DNA replication, depending on the multiprotein complex cohesin (Nasmyth et al. 2000). In order to resolve sister chromatids in animal cells, however, most cohesin dissociates from the chromosome arms in a process known as the "prophase pathway" (Hirano 2000; Peters et al. 2008), which is partially dependent on the phosphorylation of cohesin by mitotic kinases during prophase and prometaphase (Hauf et al. 2005). Nevertheless, centromeric cohesin is retained until metaphase due to the function of shugoshin proteins (Sgo/ MEI-S332) (Salic et al. 2004; Kitajima et al. 2005; Lee et al. 2005; McGuinness et al. 2005; Watanabe 2005). Mammalian

${ }^{3}$ Present address: European Molecular Biology Laboratory, Meyerhofstrasse 1, D-69117 Heidelberg, Germany.

${ }^{4}$ Corresponding author.

E-MAIL ywatanab@iam.u-tokyo.ac.jp; FAX 81-03-5841-1466.

Article is online at http://www.genesdev.org/cgi/doi/10.1101/gad.1945310.

Freely available online through the Genes \& Development Open Access option. shugoshin, Sgol, associates with serine-threonine protein phosphatase 2A (PP2A) to prevent the phosphorylation of cohesin, thereby preserving centromeric cohesion throughout prophase until metaphase (Kitajima et al. 2006; Riedel et al. 2006). At metaphase, sister kinetochores are captured by spindle microtubules emanating from the opposite spindle poles, and this bipolar attachment is stabilized by the tension generated by the pulling force of spindle microtubules and the counteracting cohesive force at the centromeres. Thus, centromeric cohesion, which is largely protected by shugoshin, is essential for establishing bipolar attachment (Kitajima et al. 2005; McGuinness et al. 2005). In germ cells, centromeric cohesin is protected throughout meiosis I by the action of another shugoshin, mSgo2, in mice (Lee et al. 2008; Llano et al. 2008). Thereby, sister chromatid cohesion is preserved at centromeres until meiosis II, when, as in mitosis, equational chromosome segregation occurs, depending on the residual cohesion at centromeres. hSgo2 might also act in cohesion protection during mitosis (Kitajima et al. 2006).

At the inner centromere, Aurora B kinase plays a central role in the tension-dependent reorientation (Tanaka et al. 2002; Ditchfield et al. 2003; Hauf et al. 2003), which is mediated partly by the phosphorylation of the microtubule-kinetochore linker proteins such as Daml and Hec1/ 
Ndc80, and the KNL/Mis12 complex /Cheeseman et al. 2006; DeLuca et al. 2006; Ciferri et al. 2008; Welburn et al. 2010); the phosphorylation of these proteins by Aurora B destabilizes erroneous microtubule attachment, thus promoting reorientation. In contrast, bipolar attachment would produce tension across centromeres, which keeps the kinetochores away from Aurora B kinase, thereby potentially suppressing the phosphorylation of the linker proteins (Cheeseman and Desai 2008; Guimaraes et al. 2008; Miller et al. 2008; Tanaka 2008; Liu et al. 2009; Welburn et al. 2010). In addition to the linker proteins, microtubule depolymerizing kinesin-13s MCAK or Kif2a might play a crucial role in establishing biorientation under the regulation of Aurora B (Andrews et al. 2004; Kline-Smith et al. 2004; Lan et al. 2004; Ohi et al. 2007). A recent report suggests a potential link between MCAK localization and hSgo 2 function at centromeres, while the molecular link between them remains elusive (Huang et al. 2007).

Here we first did a careful investigation of shugoshindepleted HeLa cells to verify that hSgo 2 is required not only for chromosome congression, but also to protect centromeric cohesion, presumably in a redundant capacity with hSgol. These functions apparently overlap with those of Aurora B. Correspondingly, we found that hSgo 2 is the in vivo substrate of Aurora B, and that only when hSgo 2 is phosphorylated by Aurora B is hSgo2 able to recruit both
MCAK and PP2A, factors required for chromosome congression and the protection of centromeric cohesion, respectively. Based on these findings, and in light of a study in spermatocytes, we conclude that mammalian Sgo2 is a hitherto unknown crucial substrate of Aurora B, a kinase setting faithful chromosome segregation.

\section{Results}

\section{hSgo2 plays a dual role in chromosome congression and retention of centromeric cohesion}

Two shugoshins, hSgol and hSgo2, play essential roles in mitotic progression in HeLa cells. While hSgol is recognized as a centromeric protector in somatic cells, the requirement of $\mathrm{hSgo} 2$ for centromeric protection is controversial (Kitajima et al. 2006; Huang et al. 2007). To resolve this issue, we examined the timing of the loss of sister chromatid cohesion in hSgo-depleted cells in a precise manner. We prepared highly synchronous mitotic cells by mitotic shake-off after double-thymidine block and release and siRNA treatment (Supplemental Fig. S1). The cells were collected over the next $14 \mathrm{~h}$ and prepared for chromosome spreads (Fig. 1A). Control cells quickly exited mitosis in the first $2 \mathrm{~h}$, showing a peak of sister chromatid separation at $1 \mathrm{~h}$ (Fig. 1B,C). In contrast, cells treated with hSgol or hSgo2 siRNA exhibited mitotic delay or arrest. Nevertheless, the mitotic population gradually decreased,
A
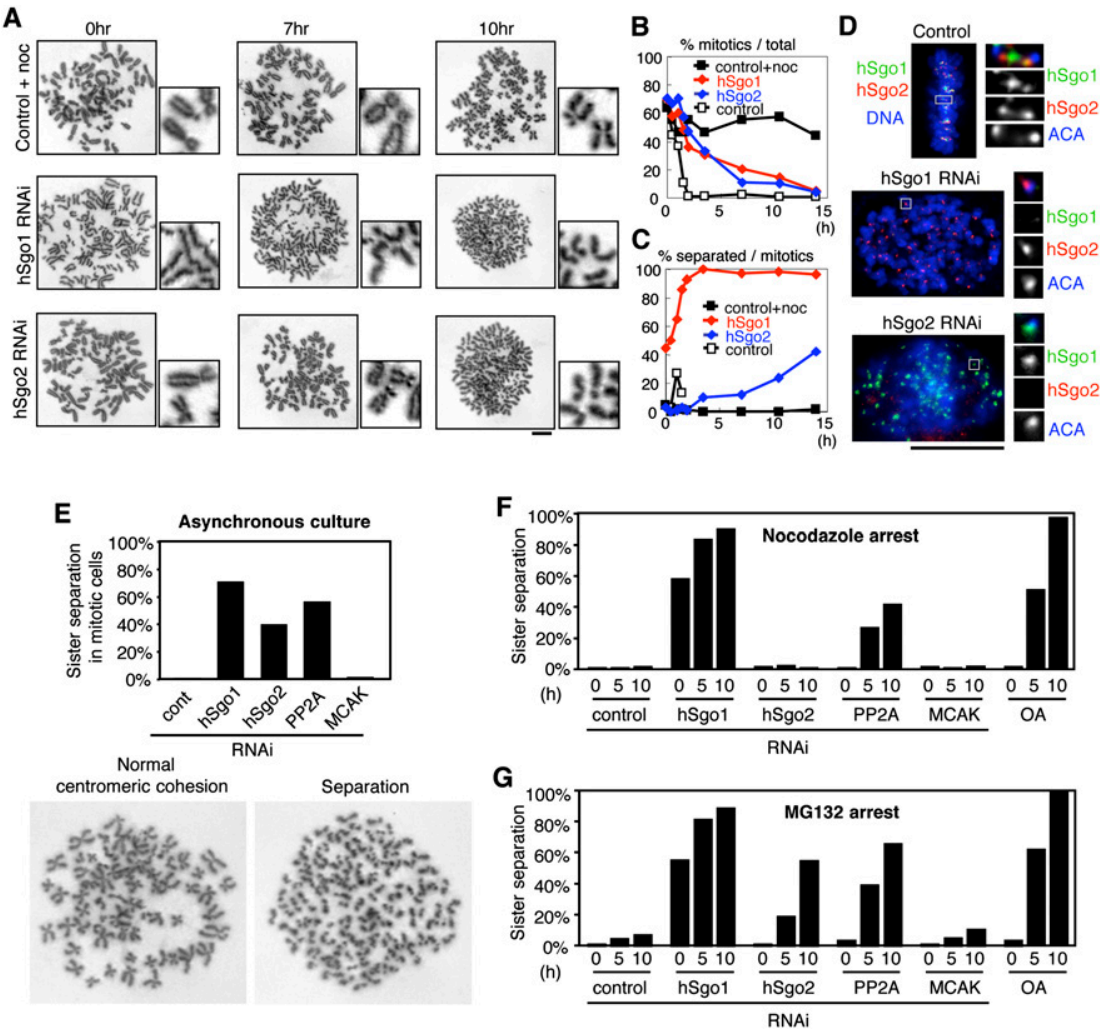

Figure 1. Mitotic defects of hSgo2 RNAi in HeLa cells. (A) Synchronized mitotic HeLa cells after mock treatment or treatment with hSgol or hSgo2 siRNA were harvested by mitotic shake-off and transferred into fresh medium with or without nocodazole (noc). Samples taken at the indicated time points after transfer were examined by chromosome spreading and Giemsa staining (see Supplemental Fig. 1 for experimental scheme). (B) The frequency of mitotic cells as a percentage of total cell numbers $\mid n>$ 200). (C) The frequency of the mitotic cells exhibiting sister chromatid separation as a percentage of all mitotic cells $(n>100)$. (D) Immunostaining of cells with antihSgo1, anti-hSgo2, and Hoechst 33342 (DNA). ACA staining is shown on the right. A magnified image of paired (in control) or separated (in hSgol or hSgo2 RNAi) kinetochores is shown on the right. (E) HeLa cells were mock-treated or treated with hSgol, hSgo2, PP2A-A, or MCAK siRNA. After incubation for $48 \mathrm{~h}$ (72 $\mathrm{h}$ in MCAK RNAi), mitotic cells were prepared and examined by chromosome spreading and Giemsa staining. The frequency of the cells exhibiting sister chromatid separation among total mitotic cells is shown. $(F, G)$ HeLa cells were mock-treated or treated with hSgo1, hSgo2, PP2A-A, or MCAK siRNA. After incubation for $12 \mathrm{~h}$ (36 h in MCAK RNAi), cells were treated with thymidine for $24 \mathrm{~h}$ and released for $11.5 \mathrm{~h}$. After incubation with nocodazole (F) or MG132 $(G)$ for $0.5 \mathrm{~h}$, mitotic cells were harvested by shake-off and further incubated with medium containing the drug. The frequency of precocious separation was determined at the indicated times (in hours) after shake-off. In the mock-treated culture, okadaic acid (OA) was also added at $0 \mathrm{~h}$ and examined for sister separation. 
mainly due to cell death (Fig. 1B; see also below). Notably, most of the hSgol-depleted mitotic cells underwent separation of sister chromatids in the first $2 \mathrm{~h}$. In contrast, in $\sim 88 \%$ of hSgo 2 RNAi cells, sister chromatids did not separate until $7 \mathrm{~h}$ after shake-off; the separation gradually increased to $\sim 42 \%$ at $14 \mathrm{~h}$ (Fig. 1A,C). By immunostaining centromeres in fixed hSgo2 RNAi cells, we confirmed that sister chromatid cohesion was intact in early mitosis, whereas separation appeared at a later time (Supplemental Fig. S2A). This separation of sister chromatids occurred due to a defect in the protection of centromeric cohesion rather than premature entry into anaphase, since Cyclin B was positive in these cells (Supplemental Fig. S2B,C). Moreover, centromeric localization of hSgol was intact in the hSgo2-depleted cells even after sister separation (Fig. 1D; Supplemental Fig. S3), suggesting that hSgo2 contributes to centromeric protection independently of centromeric hSgol localization. Live-imaging analyses verified that the initial mitotic arrest in hSgo2 RNAi cells is due to the defects in chromosome alignment (Supplemental Fig. S4; Huang et al. 2007). Accordingly, the mitotic arrest caused by hSgo2 RNAi is spindle checkpoint-dependent (Supplemental Fig. S5).

In contrast to the results obtained in asynchronous RNAi cells, hSgo2 RNAi cells did not show centromeric separation when spindle formation was prevented in the synchronous cultures by the addition of nocodazole, and the cell cycle was arrested at prometaphase (Fig. 1E,F). Recent reports suggest that tension across centromeres alleviates the ability of shugoshin to protect cohesin, even in normal cells (Gomez et al. 2007; Lee et al. 2008). Given that the separation of sisters in hSgo2 RNAi cells occurs only after entering metaphase-like arrest (Supplemental
Fig. S4), the defect in centromeric protection might be exposed when centromeres come under tension or simply as a consequence of spindle microtubule attachment. When the cell cycle was arrested at metaphase by the addition of the proteasome inhibitor MG132, $>50 \%$ of hSgo2 RNAi cells exhibited centromere separation (Fig. 1G), whereas cells treated with taxol, which stabilizes the spindle, did not produce centromeric separation, as in nocodazole-treated cells (Supplemental Fig. S6). In contrast, the depletion of hSgol or inhibition of PP2A by okadaic acid resulted in sufficient separation even in the presence of nocodazole (Fig. 1F). Thus, unlike hSgol or PP2A, hSgo2 is not required for centromeric cohesion in normal metaphase as reported previously (Huang et al. 2007), but is required for the retention of centromeric cohesion in perturbed metaphase, in which centromeres are exposed to tension for a prolonged time (see the Discussion).

\section{Centromeric localizations of both PP2A and MCAK are dependent on $\mathrm{hSgo2}$, but are independent of each other}

Consistent with the dual role of hSgo2, previous reports suggest that at least two putative effecter molecules, PP2A and MCAK, localize at centromeres in a hSgo2dependent manner (Fig. 2A; Kitajima et al. 2006; Huang et al. 2007). Intriguingly, the centromeric localizations of PP2A and MCAK are not interdependent (Fig. 2A), suggesting that these molecules are recruited independently to centromeres depending on hSgo2. MCAK RNAi cells do not show sister chromatid separation even under metaphase arrest (Fig. 1G), although they show defects similar to hSgo2 RNAi cells in chromosome congression (Supplemental Fig. S7).
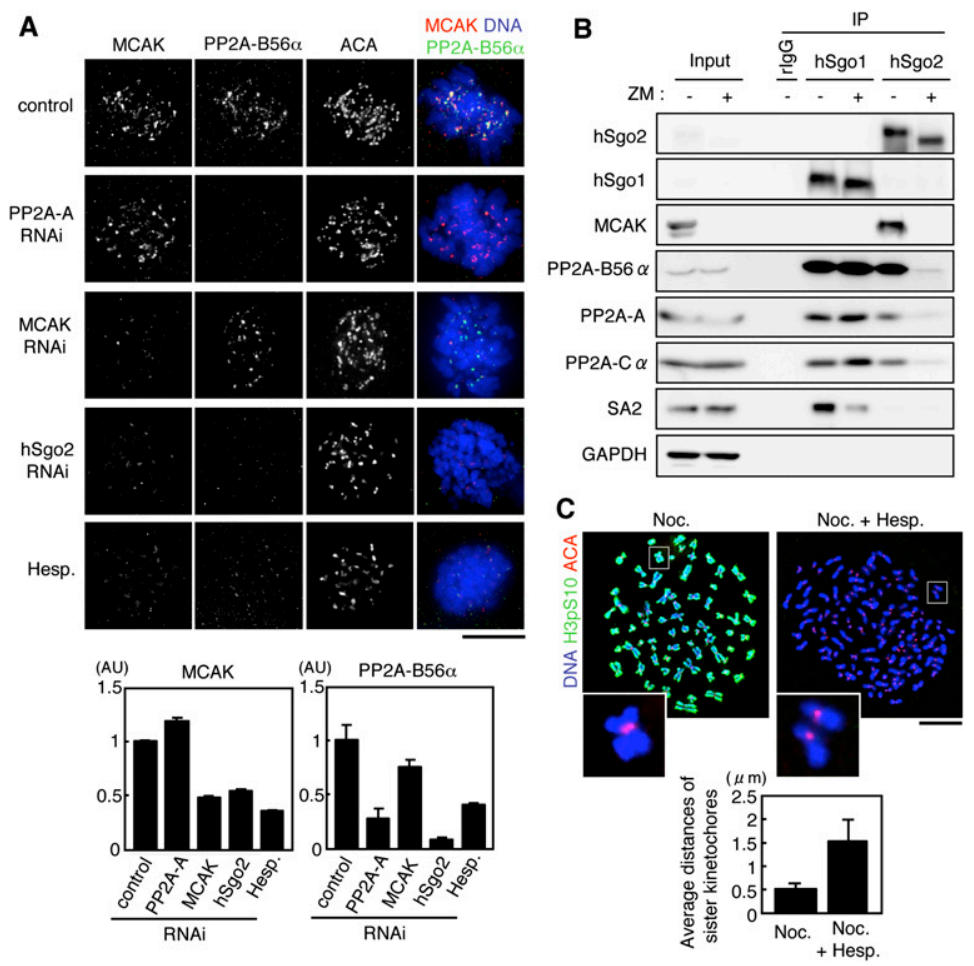

Figure 2. Centromeric localizations of PP2A and MCAK are both dependent on hSgo2 and Aurora B, but are independent of each other. (A) Prometaphase cells were stained with ACA, anti-MCAK, and antiPP2A-B56 $\alpha$ at $48 \mathrm{~h}$ after treatment with siRNA against PP2A-A, MCAK, or hSgo2. DNA was counterstained with Hoechst 33342. Relative fluorescent intensities of centromeric PP2A-B56 $\alpha$ (left) and MCAK (right) toward ACA were quantified at 10 centromeres in each cell. The average value over 10 cells is shown. Error bars, SEM $(n>10)$. (B) HeLa cells were once arrested by nocodazole and incubated with MG132 and ZM447439 for $3 \mathrm{~h}$. Immunoprecipitates (IP) obtained from cell extracts by anti-hSgol or anti-hSgo2 antibody or control IgG were analyzed by immunoblot using antibodies against the indicated proteins. (Input) $0.5 \%$ of whole soluble extract. $(C)$ Inhibition of Aurora B impairs centrometric cohesion. Synchronized mitotic HeLa cells were harvested by mitotic shake-off, treated with nocodazole for $2 \mathrm{~h}$, and incubated further with or without hesperadin for $3 \mathrm{~h}$. After hypotonic treatment, the cells were spun onto slide glasses and stained with ACA and anti-phospho-H3S10. DNA was counterstained with Hoechst 33342. ACA distances between sister centromeres were averaged over 10 centromeres in each cell. The average value for 10 cells is shown. Error bars, SD ( $n=10$ cells). Bars, $10 \mu \mathrm{m}$. 
Thus, although MCAK might be a crucial target of hSgo2 for chromosome alignment, the function of MCAK is dispensable for the hSgo2-dependent centromeric protection, while PP2A would be responsible for it.

hSgo 2 forms a complex with PP2A (Kitajima et al. 2006; Xu et al. 2009), while its interaction with MCAK has not been detected. To explore this possibility, we prepared cell extracts including the chromatin fraction from prometaphase-arrested cells, in which MCAK accumulates at centromeres depending on hSgo2. An immunoprecipitation assay detected the coprecipitation of hSgo2 with MCAK as well as PP2A (Fig. 2B), providing strong evidence that hSgo2 recruits these proteins to centromeres by forming a complex. Given that both the centromeric localization of MCAK and chromosome alignment are under the control of Aurora B (Fig. 2A; Ditchfield et al. 2003; Hauf et al. 2003; Andrews et al. 2004; Kline-Smith et al. 2004; Lan et al. 2004), Aurora B might affect the interaction of hSgo2 with MCAK. We could not evaluate this possibility in this experiment, since the MCAK protein level was greatly reduced by the addition of ZM447439, an inhibitor of Aurora B (Fig. $2 B$; Ditchfield et al. 2003). However, the interaction of hSgo2 with PP2A was impaired under these conditions (Fig. 2B) due to the fact that the centromeric localization of PP2A is diminished by inhibiting Aurora B (Fig. 2A). Notably, hSgo2 coprecipitates efficiently with PP2A-B56 $\alpha$ more than with PP2A-A or PP2A-C if the extracts contained the full chromatin fraction (Fig. 2B), although previous two-hybrid assays, in vitro binding assays, and immunoprecipitation using cytoplasmic extracts could not detect the direct interaction between hSgo2 and PP2A-B56 $\alpha$ (Kitajima et al. 2006; Xu et al. 2009). These results suggest that, especially on chromatin, hSgo2 may interact directly with PP2AB56 $\alpha$ among the PP2A complex proteins in an Aurora B-dependent manner.

Finally, the comparison of immunoprecipitates of hSgol and hSgo 2 revealed that hSgol associates with PP2A and cohesin SA2 but not MCAK, although hSgo2 does not associate with SA2 (Fig. 2B). Moreover, the interaction between hSgol and PP2A is not dependent on Aurora B, while the interaction between hSgol and SA2 is dependent. These results illuminate the partly overlapping but distinct biochemical properties of these two shugoshin proteins in human mitotic extracts (see the Discussion).

\section{Aurora $B$ is required for centromeric protection}

Although the importance of Aurora B for chromosome alignment is well established, its requirement for centromeric protection has been suggested, but not unequivocally demonstrated, in mammalian cells (Kawashima et al. 2007), because arm cohesion persists when Aurora B is inhibited (Losada et al. 2002; Dai et al. 2006). To overcome this problem, we first treated mitotic cells with nocodazole, resulting in the alleviation of cohesion along the chromosome arms but not at the centromeres, and then added hesperadin, another Aurora B kinase inhibitor (Hauf et al. 2003). By using this strategy, we could indeed verify the requirement of Aurora B for centromeric protection (Fig. 2C). It is notable, however, that the cohesion defect by
Aurora B inhibition might be more pronounced than that produced by hSgo 2 depletion, and this may be explained by the partial defects in hSgol localization under these conditions (Dai et al. 2006; Kawashima et al. 2007). Nevertheless, these analyses support the notion that chromosome alignment and centromeric protection are impaired by Aurora B inhibition, showing some functional overlap of Aurora B with hSgo2.

\section{Aurora B phosphorylates hSgo2}

To explore the possibility that hSgo 2 is phosphorylated directly by Aurora B, we bacterially expressed full-length hSgo2 fused with GST and performed an in vitro phosphorylation reaction. Our assay indicated that recombinant hSgo 2 is efficiently phosphorylated by Aurora B in vitro (see below). To determine the phosphorylation sites, we divided the hSgo2 protein into three domains: $\mathrm{N}$ terminus, middle, and C terminus (Fig. 3A, hSgo2-N, hSgo2-M, and hSgo2-C). The subsequent phosphorylation assay revealed that the Aurora B phosphorylation sites exist mainly in the hSgo2-N and hSgo2-M regions (Fig. 3A). hSgo2-N carries nine weak consensus sequences for Aurora B substrate (R/KXS/T), and the substitution of all of these S/T sites with alanine (hSgo2-N9A) abolished the phosphorylation (Fig. 3A). Although the hSgo2-M region carries numerous Aurora B consensus sequences, alanine substitution assays identified two of them (T537 and T620) as major phosphorylation sites (Fig. 3A; data not shown). A peptide sequence including T620 is repeated tandemly in the hSgo2-M fragment (Fig. 3A; Supplemental Fig. S8), and these sites are slightly phosphorylated by Aurora B in vitro (Fig. 3A). Therefore, these sites were included to make the middle region of hSgo 2 nonphosphorylatable. We then prepared full-length hSgo2 carrying the alanine substitutions in the $\mathrm{N}$-terminal and middle regions (hSgo2-N9A and hSgo2-M5A), and confirmed that these sites substantially contribute to the phosphorylation of the full-length hSgo2 protein by Aurora B in vitro (Fig. 3B). The hSgo2-23A protein, which carries alanine substitutions not only in the $\mathrm{N}$-terminal and middle regions, but also in the $\mathrm{C}$-terminal region (nine consensus sequences), nearly completely abolished phosphorylation by Aurora B (Fig. 3B).

To examine whether hSgo 2 is phosphorylated in vivo, we prepared a polyclonal antibody raised against a phospho-peptide (pT537) that locates in the middle region of hSgo2. The anti-pT537 antibody recognized the hSgo2 protein only when it was incubated with Aurora B and ATP in vitro (Fig. 3C). We then precipitated hSgo2 proteins from prometaphase cells and analyzed the phosphorylation at $\mathrm{T} 537$ by immunoblot. hSgo 2 was detected by anti-pT537, but this signal was substantially reduced when hSgo2 was prepared from cells treated with hesperadin (Fig. 3D). Immunostaining by anti-hSgo2 as well as anti-pT537 confirmed that hSgo 2 is phosphorylated at centromeres, and this phosphorylation is retarded by hesparadin (Fig. 3E). These results verify that at least one of the major in vitro phosphorylation sites of hSgo2 is phosphorylated by Aurora B in vivo. 

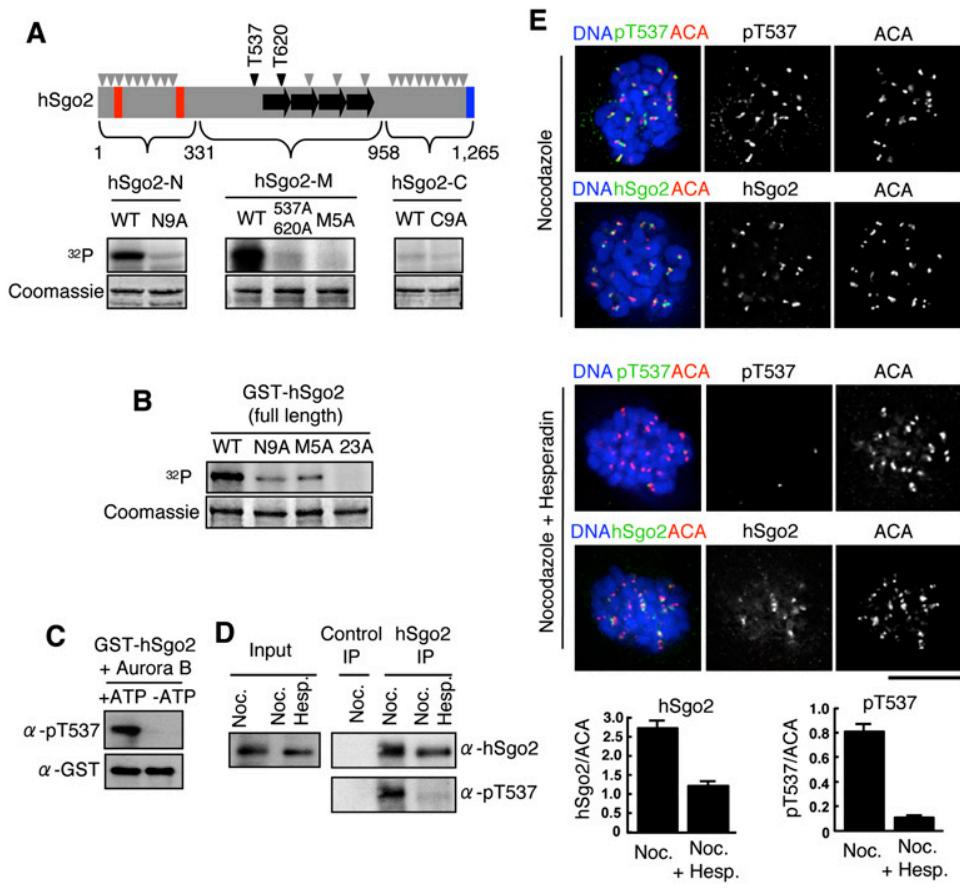

Figure 3. Aurora B phosphorylates hSgo2. (A) A schematic drawing of the $\mathrm{hSgo} 2$ protein with conserved coiled-coil (red) and basic (blue) regions. Black arrows indicate repeat sequences within $\mathrm{hSgo} 2$, and arrowheads indicate the position of consensus sequences for Aurora B. GST-fused hSgo2 fragments (N-terminal, middle, and C-terminal region) were expressed and purified from bacteria. Those with mutations in the Aurora B consensus were also prepared. After incubation with recombinant His-Aurora B in the presence of $\gamma^{32} \mathrm{P}$-ATP, the fragments were analyzed by SDS-PAGE and autoradiography. $(B)$ Full-length hSgo2 proteins fused with GST were assayed for in vitro phosphorylation with GST-Aurora B. (C) Full-length GST-hSgo2 was incubated with His-Aurora B in the presence $(+)$ or absence (-) of ATP, and phosphorylation was detected by immunoblot with anti-pT537 antibody and anti-GST antibody. $(D)$ Anti-hSgo2 or control rabbit IgG immunoprecipitation was conducted using lysates of nocodazole-arrested cells treated with DMSO or hesperadin, and immunoblot was performed with anti-hSgo2 and anti-pT537 antibodies. (E) Synchronized mitotic HeLa cells were harvested by mitotic shake-off, treated with nocodazole for $2 \mathrm{~h}$, and incubated further with or without hesperadin for $3 \mathrm{~h}$. Cells were fixed with $2 \%$ PFA and spun onto slide glasses by cytospin, then immunostained with ACA and anti-hSgo2 or ACA and anti-pT537. Relative fluorescent intensities of centromeric hSgo2 and pT537 toward ACA were quantified at 10 centromeres in each cell. The average value over 10 cells is shown. Error bars, SEM ( $n>10$ cells). Bars, $10 \mu \mathrm{m}$.

The association of hSgo2 with PP2A and MCAK requires Aurora B-dependent phosphorylation in vitro

Assuming that the phosphorylation of hSgo2 by Aurora B may regulate the association of hSgo2 with PP2A and MCAK, we prepared bacterially produced hSgo2 protein and examined the association with MBP-fused PP2A-B56 $\alpha$ (a subunit mediating the localization of PP2A) or MCAK by pull-down assay (Fig. 4A). We confirmed that MBP itself does not associate with hSgo2 (Fig. 4B). Remarkably, the association of hSgo2 with PP2A-B56 $\alpha$ was detected only when both hSgo2 and PP2A-B56 $\alpha$ were incubated with Aurora B and ATP prior to the binding assay, whereas the hSgo2-N9A mutant protein, but not hSgo2-M5A, abolished this association (Fig. 4C). We verified that PP2AB56 $\alpha$ was indeed phosphorylated by Aurora B in vitro (Supplemental Fig. S9). These results suggest that only when the $\mathrm{N}$ terminus of hSgo2 is phosphorylated by Aurora B can hSgo2 selectively associate with the phosphorylated form of PP2A-B56 $\alpha$. Similarly, the association of hSgo2 with MCAK was detected only when hSgo2 was phosphorylated by Aurora B, while this association does not require the phosphorylation of MCAK (Fig. 4D). Crucially, this association was abolished in hSgo2-M5A but not hSgo2-N9A, indicating that hSgo2 can associate with MCAK only when the middle region of hSgo2 is phosphorylated by Aurora B. These results suggest that hSgo2 associates directly with PP2A and MCAK, depending on phosphorylation in the $\mathrm{N}$-terminal and middle regions of hSgo2, respectively. Consistent with this fact, bead-bound MCAK could pull down PP2A-B56 $\alpha$ only when phosphorylated hSgo2 was present, and the association between
MCAK and hSgo2 was not altered by the addition of excess PP2A-B56 $\alpha$ (Fig. 4E), implying that a single hSgo2 protein associates simultaneously with MCAK and PP2A-B56 $\alpha$.

\section{Phosphorylation of hSgo2 by Aurora B is crucial for the recruitment of PP2A and MCAK to centromeres}

To evaluate the significance of the foregoing in vitro binding assays, we examined the ability of the nonphosphorylatable forms of hSgo2 to recruit PP2A or MCAK to centromeres in vivo. The expression of a complementary DNA encoding RNAi-resistant EGFP-hSgo2 (or its nonphosphorylatable forms) in HeLa Flp-In cells followed by hSgo2 RNAi allowed us to remove endogenous hSgo2 and evaluate the ability of the exogenously expressed hSgo 2 to recruit PP2A and MCAK to centromeres (see Supplemental Fig. S10A). Remarkably, the ability to recruit PP2A to centromeres was lost in hSgo2-N9A but was retained in hSgo2-M5A, whereas the ability to recruit MCAK was lost in hSgo2-M5A but not in hSgo2-N9A (Fig. 5A,B). These results are highly consistent with those of the in vitro binding assay of these hSgo2 mutant proteins (Fig. 4). Despite the defect in PP2A or MCAK recruitment, all of these mutant hSgo2 proteins localized at centromeres. Moreover, hSgo2-23A, which is mostly free from phosphorylation by Aurora $\mathrm{B}$, also localized at centromeres, even though the recruitment of both PP2A and MCAK was abolished (Fig. 5A,B; Supplemental Fig. S10B). Thus, although Aurora B activity may contribute to the centromeric localization of hSgo2 (Fig. 3E; Huang et al. 2007), the phosphorylation of hSgo2 is not relevant to this regulation. Taken together, these results suggest that the Aurora B-dependent 


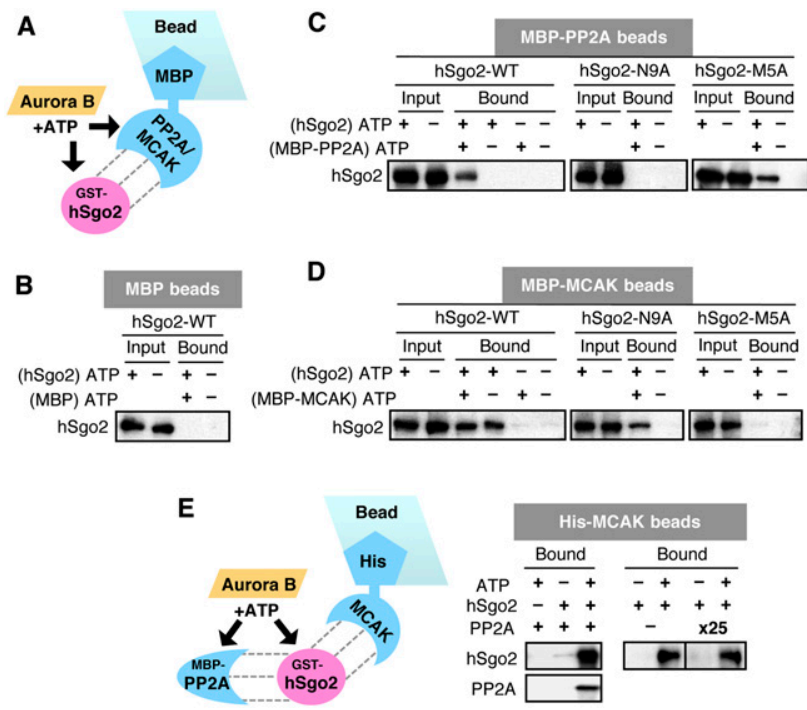

Figure 4. hSgo2 interacts with PP2A and MCAK, depending on phosphorylation by Aurora B. (A) Experimental scheme of the in vitro pull-down assay. Recombinant GST-hSgo2, MBP-PP2AB56 $\alpha$, MBP-MCAK, and His-Aurora B were purified from bacteria. Amylose bead-conjugated MBP-tagged proteins and GSThSgo2 were incubated in separate tubes with His-Aurora B with or without ATP. After inhibiting Aurora B activity by adding EDTA, the tagged proteins were mixed for MBP pull-down assay. The binding of GST-hSgo2 was detected by immunoblot with anti-GST. $(B-D)$ GST-hSgo2 pulled down by MBP $(B)$, MBPPP2A-B56 $\alpha(C)$, or MBP-MCAK $(D)$ was detected by immunoblot with anti-GST antibody. Ten percent inputs were similarly analyzed. (E, left) GST-hSgo2 and/or MBP-PP2A-B56 $\alpha$ were mixed, incubated with Aurora B in the presence or absence of ATP, and pulled down by His-MCAK beads. (Right) The pulldown of hSgo 2 by MCAK beads was not competed by 25 times excess of PP2A-B56 $\alpha$ protein.

phosphorylations of hSgo2 at the N-terminal and middle regions mediate the recruitment of PP2A and MCAK to centromeres, respectively.

To investigate the importance of hSgo2 phosphorylation in controlling chromosome alignment and centromeric protection, we examined the ability of the nonphosphorylatable forms of hSgo2 to complement the defects in hSgo2 RNAi cells. To avoid overlooking the centromeric protection defects observable only in perturbed mitosis, we arrested cells at metaphase with addition of MG132 (Fig. 5C). Although wild-type hSgo2 complements defects of both alignment and protection, hSgo2-23A does not complement either defect, suggesting that the phosphorylation of hSgo2 by Aurora B is essential for hSgo2 function. Strikingly, hSgo2-M5A substantially complements centromeric protection without restoring normal chromosome alignment, similar to MCAK RNAi cells (Fig. 5C). In contrast, hSgo2-N9A complements the alignment defect without complementation in centromeric protection. Liveimaging analyses are consistent with these results (Supplemental Fig. S11). These data suggest that hSgo2 regulates chromosome alignment and retention of centromeric protection mainly by recruiting MCAK and PP2A to centro- meres, and that the recruitment of these factors largely depends on hSgo2 phosphorylations by Aurora B.

\section{Centromeric localization of PP2A and MCAK \\ in germ cells requires Aurora B activity and $\mathrm{mSgo} 2$ phosphorylation}

Because mSgo2-PP2A plays a predominant role in the protection of centromeric cohesin in mouse germ cells (Lee et al. 2008; Llano et al. 2008), we examined the regulation of PP2A localization by Aurora B activity and mSgo2 phosphorylation in spermatocytes. The in vitro cultures of spermatocytes were treated with ZM447439 and immunostained for the localization of $\mathrm{mSgo} 2$ and PP2A-A. The results indicate that, although the localizations of both $\mathrm{mSgo} 2$ and PP2A are lost from centromeres at later time points, PP2A localization diminishes during the middle time stages, especially from centromeres, which lose mSgo2 phosphorylation at T521 (comparable with T537 of hSgo2) but still retain mSgo2 localization (Fig. 6A). We did not find any PP2A localization in the pT521negative cells $(n=40)$. Because the PP2A localization at centromeres depends largely on $\mathrm{mSgo} 2$ protein in germ cells (Lee et al. 2008), these results imply that the phosphorylation of $\mathrm{mSgo} 2$ by Aurora $\mathrm{B}$ is crucial for the localization of PP2A at centromeres. Given that MCAK also localizes at centromeres in germ cells (Parra et al. 2006), we performed a comparable experiment using an MCAK antibody. The results similarly suggest that $\mathrm{mSgo} 2$ phosphorylation by Aurora B is important for the centromeric localization of MCAK (Fig. 6B). Taken together, these results argue that the crucial regulation of hSgo2 by Aurora $\mathrm{B}$, as revealed in HeLa cells, may be applicable to mouse germ cells, where $\mathrm{mSgo} 2$ rather than $\mathrm{mSgol}$ plays a predominant role (Lee et al. 2008).

\section{Discussion}

By comparing the phenotypes of hSgol RNAi and hSgo2 RNAi HeLa cells and assaying the immunoprecipitates of hSgol and hSgo2, we verified that hSgo2 plays a characteristic role in chromosome congression, at least partly through recruiting MCAK to centromeres, and also contributes to the centromeric protection by recruiting PP2A (Fig. 7). The latter function of hSgo2 may play an auxiliary role, since the defect in the protection is much stronger in cells depleted of hSgol than hSgo2. However, it is notable that PP2A localization at centromeres largely depends on hSgo2 rather than hSgol, while hSgol plays a predominant role in centromeric protection by associating with PP2A in somatic cells (Fig. 2B; Supplemental Fig. 12; Kitajima et al. 2006; Tang et al. 2006; Huang et al. 2007). Crucially, in mitotic extracts, cohesin SA2, the primary dephosphorylation target for protection (Hauf et al. 2005; Kitajima et al. 2006), coprecipitates only with hSgol but not with hSgo2 (Fig. 2B). Thus, we assume that the hSgol-PP2A complex associates directly with and dephosphorylates mitotic cohesins to protect them from the prophase dissociation pathway, while hSgo2 plays a role in enriching PP2A to supply it to centromeric hSgol 

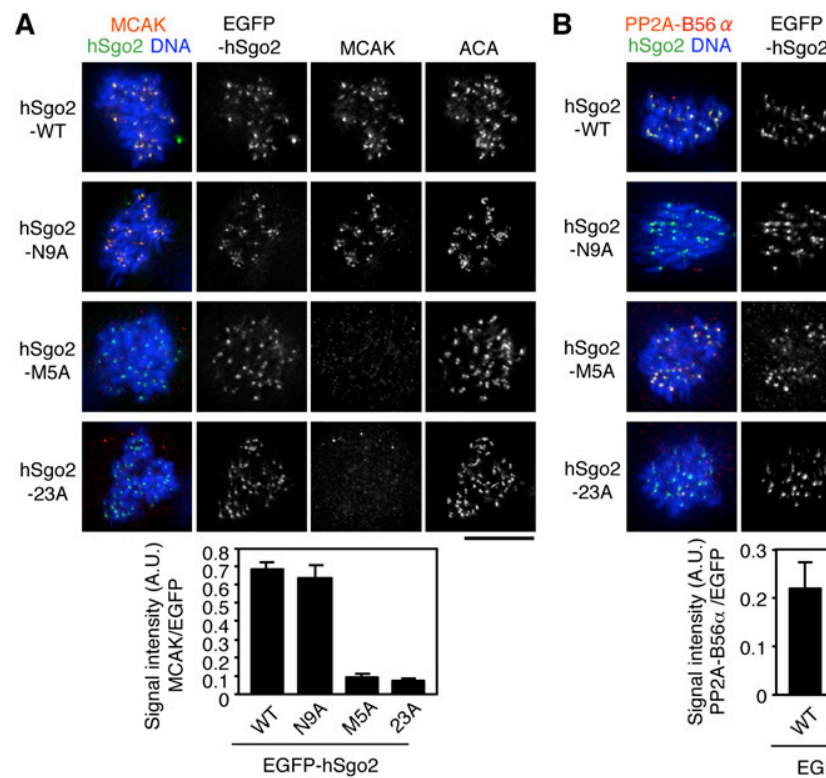

A

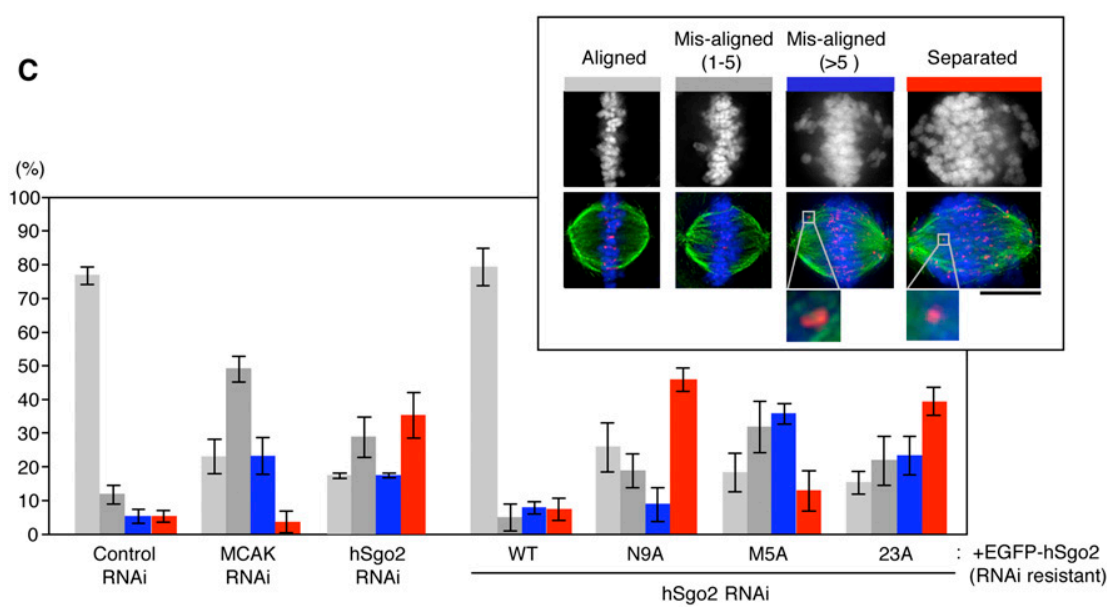

Figure 5. Phosphorylation of hSgo2 by Aurora B is crucial for the recruitment of PP2A and MCAK and their functions at centromeres. $(A, B)$ HeLa Flp-In cells expressing RNAi-resistant EGFP-hSgo2 (wild-type or indicated mutant form) were transfected with siRNA against endogenous hSgo2, incubated for $12 \mathrm{~h}$, and treated with thymidine for $24 \mathrm{~h}$. After thymidine release, the cells were incubated for $12 \mathrm{~h}$, fixed, and immunostained with ACA, anti-EGFP, and anti-MCAK $(A)$ or anti-PP2A-B56 $\alpha(B)$. DNA was counterstained with Hoechst 33342. Relative centromeric signal intensities of MCAK or PP2A-B56 $\alpha$ toward EGFP-hSgo2 were counted at 10 centromeres in each cell. The average value over 10 cells is shown. Error bars, SEM $(n>10$ cells). (C) HeLa Flp-In cells expressing RNAiresistant EGFP-hSgo2 (wild-type or the indicated mutant form) were transfected with siRNA against endogenous hSgo2, incubated for $12 \mathrm{~h}$, and treated with thymidine for $24 \mathrm{~h}$. Cells were released for $15 \mathrm{~h}$ and treated with MG132 for $3 \mathrm{~h}$, and then fixed and stained with ACA, anti-EGFP, and anti-tubulin. DNA was counterstained with Hoechst 33342 . MCAK RNAi cells were similarly examined as a reference, while PP2A RNAi cells were not applicable for this assay because of the defects in the spindle integrity (Kitajima et al. 2006). Mitotic cells expressing EGFP and forming a bipolar spindle were classified into four categories. Error bars, SD $(n=3$ experiments). Representative cells in each category are shown. Bars, $10 \mu \mathrm{m}$. and/or to supplementarily dephosphorylate mitotic cohesin; hSgo2-PP2A plays a predominant role in centromeric protection during meiosis (Lee et al. 2008; Llano et al. 2008), possibly by recognizing meiotic cohesin directly. This scenario is tenable because the crucial substrate of shugoshin-PP2A in meiosis is the cohesin subunit Rec8 rather than SA2, at least in yeasts (Ishiguro et al. 2010; Katis et al. 2010). Although further studies are required to reveal the precise difference in centromeric protection by hSgol and hSgo2, or between mitosis and meiosis, our present studies establish that hSgo 2 plays a dual role in chromosome congression and retention of centromeric cohesion in HeLa cells. Because centromeric cohesion defects by hSgo2 RNAi were recapitulated in normal fibroblast cells (Supplemental Fig. S13), this cohesion defect, which appears only in combination with congression defect, is likely applicable to human somatic cells in general. Although $\mathrm{mSgo}$-deficient mice are reportedly viable (Llano et al. 2008), we suggest that mSgol or other factors might compensate for the somatic mSgo2 function in mice.
Our analyses revealed the regulatory manner of centromeric recruitment of PP2A and MCAK by hSgo2. Both PP2A and MCAK coprecipitate with hSgo2, indicating the formation of the complex. Moreover, the depletion of PP2A by RNAi does not impair MCAK localization, and, conversely, MCAK RNAi does not impair PP2A localization. Thus, the centromeric localizations of PP2A and MCAK are regulated in parallel, but both are dependent on hSgo2. Crucially, Aurora B kinase regulates the ability of hSgo2 for the recruitment of these effecter molecules to centromeres. Our analyses suggest that hSgo2 phosphorylation in the $\mathrm{N}$-terminal coiled-coil region is crucial for the association with PP2A, its recruitment to centromeres, and centromeric protection of cohesion, whereas phosphorylation in the middle region promotes the association with MCAK, its recruitment to centromeres, and chromosome alignment. It should be noted that, although previous RNAi or inhibitor assays could not firmly define centromeric functions of MCAK and PP2A because of additional noncentromeric functions of these proteins, our present analyses using specific hSgo2 mutants thus dispelled this concern. 
A Mouse spermatocytes

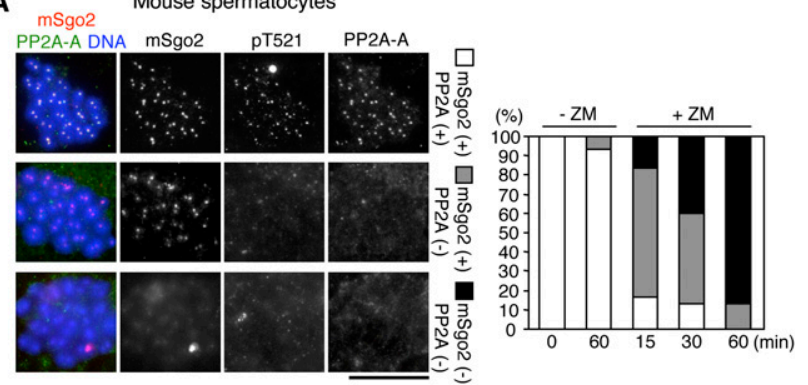

B

B $\mathrm{mSgo2}$
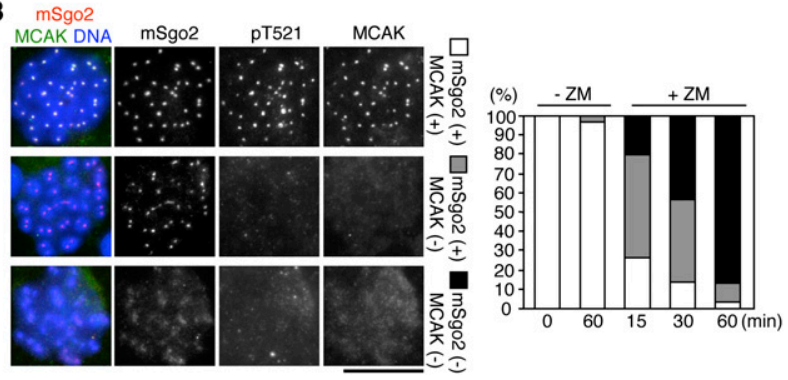

Figure 6. Centromeric localization of PP2A and MCAK requires Aurora B activity in mouse spermatocytes. $(A, B)$ The isolated spermatocytes were cultured in vitro and induced to metaphase I by the addition of $5 \mu \mathrm{M}$ okadaic acid for $6 \mathrm{~h}$. After okadaic acid was washed out (time 0 ), metaphase I spermatocytes were cultured in the absence or presence of ZM447439 for 15, 30, and $60 \mathrm{~min}$ and immunostained for mSgo2, pT521, and PP2A-A $(A)$ or MCAK $(B)$. The staining patterns were classified into three categories and quantified ( $n=30$ cells at each time point). Bars, $10 \mu \mathrm{m}$.

Our studies in spermatocytes suggest that foregoing findings in HeLa cells might be applicable to germ cells. Based on these data, we conclude that hSgo2 carries the separate capacities to mediate the centromeric functions of PP2A and MCAK, and both of these capacities are under the regulation of Aurora B-dependent phosphorylation (Fig. 7).

The target of Aurora B in the hSgo2 pathway is not only the hSgo2 protein. Our in vitro assay suggests that Aurora B phosphorylates PP2A-B56 $\alpha$ (Supplemental Fig. S9), and that this phosphorylation is also required for the association with hSgo2 (Fig. 4C). Immunoprecipitation assays also support this conclusion (Fig. 2B). This finding is remarkable because a recent study argues against the interaction between hSgo2 and PP2A-B56 $\alpha$ in vitro (Xu et al. 2009). Our data indicate that the interaction between hSgo 2 and PP2A-B56 $\alpha$, which is crucial for centromeric enrichment of PP2A (Fig. 5B; Kitajima et al. 2006), appears only when both proteins are phosphorylated by mitotic kinase Aurora B. Although the phosphorylation of MCAK by Aurora B may influence the centromeric localization of MCAK in $\mathrm{Xe}$ nopus (Zhang et al. 2007), our in vitro binding assay suggests that the phosphorylation of MCAK does not alter the association with hSgo2 (Fig. 4D). This fits with previous reports that the phosphorylation of MCAK by Aurora B is more important for regulating its microtubule-depolymerizing activity rather than centromeric localization (Andrews et al. 2004; Lan et al. 2004). Previous findings suggest that the phosphorylation of MEI-S332 (Drosophila shugoshin) by Aurora B is important for its centromeric localization (Resnick et al. 2006), whereas the Aurora B-dependent phosphorylation of shugoshin does not influence its localization in fission yeast (Kawashima et al. 2007), suggesting diversity in the requirement of Aurora B-dependent phosphorylation of shugoshin for centromeric localization. The activity of Aurora B is important for centromere targeting of hSgo 2 in HeLa cells (Fig. 3E; Huang et al. 2007) as well as mouse germ cells (Fig. 6). However, a nonphosphorylatable form of hSgo2 localizes at centromeres (Fig. 5; Supplemental Fig. S10), implying that putative scaffold proteins of hSgo2-such as heterochromatin, nucleosome, or unidentified regulators of hSgo 2 (Yamagishi et al. 2008; Kawashima et al. 2010)—might be additional targets of Aurora B in human cells. Very recently, the direct interaction between shugoshin and the Aurora B complex was shown to be important for their interdependent localization at centromeres in fission yeast, and this might be applicable to human cells (Kawashima et al. 2007; Tsukahara et al. 2010), revealing another regulatory pathway for shugoshin localization by the Aurora B complex.

In summary, our present study identifies hSgo2 as a key substrate of Aurora B, which plays a central role in ensuring faithful chromosome segregation. Moreover, our results indicate that the phosphorylations of hSgo2 are required for recruiting PP2A and MCAK to centromeres, thus providing mechanistic insight into how the phosphorylations by Aurora B contribute to centromeric protection and chromosome alignment in human cells.

\section{Materials and methods}

\section{Cell culture, stable cell lines, and RNAi}

Cells were grown in Dulbecco's Modified Eagle's Medium (DMEM) supplemented with 10\% FBS, 0.03\% L-glutamine, 100

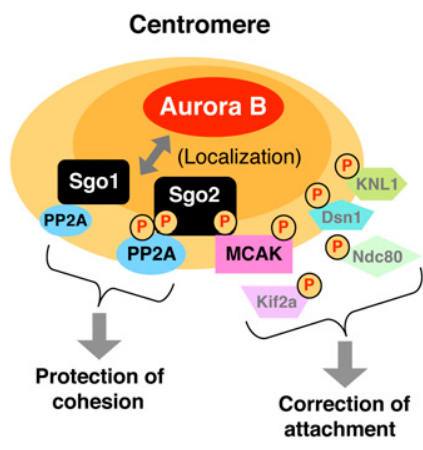

Figure 7. Schematic model of the Aurora B-dependent centromeric protection of cohesion and alignment of chromosomes. In mammals, Aurora B phosphorylates the microtubule-kinetochore linker proteins (KNL1, Dsn1, and Ndc80) as well as microtubule depolymerizing kinesin-13s (Kif2a and MCAK), factors required for the correction of attachment, and PP2A, a factor required for the protection of cohesion. The phosphorylation of Sgo2, a key substrate defined in this study, is required for recruiting PP2A and MCAK to centromeres, thus contributing to both centromeric protection and attachment correction. Shugoshin and the Aurora B complex promote their localization with each other. See the text for further details. 
$\mathrm{U} / \mathrm{mL}$ penicillin, and $100 \mu \mathrm{g} / \mathrm{mL}$ streptomycin in a moist atmosphere. HeLa-H2B-EGFP cells (provided by Dr. Toru Hirota) were supplemented with $20 \mu \mathrm{g} / \mathrm{mL}$ blasticidin, and HeLa Flp-In cells (provided by Dr. Patrick Meraldi) were supplemented with $400 \mu \mathrm{g} /$ $\mathrm{mL}$ zeocin. The Hs27 human fibroblast cell line was provided by Dr. Atsushi Enomoto. For establishment of hSgo2 mutant cell lines, we amplified hSgo2 wild-type, N9A (S26A, T29A, S53A, T76A, S146A, S236A, S247A, S266A, and S278A), M5A (T537A, T620A, T720A, S816A, W912R, and T914A), and 23A (S990A, S1047A, T1084A, S1085A, T1108A, T1205A, S1208A, S1240A, and T1250A, in addition to the N9A and M5A mutations) cDNA and inserted them into a pcDNA5/FRT/TO vector (Invitrogen). EGFP was subcloned on the $\mathrm{N}$-terminal side of hSgo2. Following the manufacturer's protocol (Invitrogen), a Flp-In HeLa host cell line was cotransfected with the pcDNA5/FRT/TO constructs and the Flp recombinase expression vector with Lipofectamine LTX (Invitrogen). Twenty-four hours after transfection, cells were selected with $200 \mu \mathrm{g} / \mathrm{mL}$ hygromycin B. RNAi was performed as described (Kitajima et al. 2005) with synthetic siRNA duplexes of hSgol, Bub1 (Kitajima et al. 2005), hSgo2, PP2A-A (Kitajima et al. 2006), BubR1 (Johnson et al. 2004), and MCAK (5'-GAUC CAACGCAGUAAUGGUTT-3'). All control samples were treated similarly, except that $\mathrm{H}_{2} \mathrm{O}$ was added instead of siRNA.

\section{Antibodies and reagents}

The following antibodies were used: rabbit polyclonal antibodies against hSgo1 (Kitajima et al. 2005), hSgo2 (Kitajima et al. 2006), and EGFP (Invitrogen); mouse monoclonal antibodies against mSgo2 (Kawashima et al. 2010), PP2A-B56 $\alpha$ Cyclin B1, GST (Santa Cruz Biotechnology), $\alpha$-tubulin (Sigma), and EGFP (Roche); goat polyclonal antibodies against PP $2 \mathrm{~A}-\mathrm{A} \alpha / \beta$ (Santa Cruz Biotechnology) and SA2 (Abcam); sheep polyclonal antibody against MCAK (provided by Drs. Jason Swedlow and Paul D. Andrew); and human polyclonal antibody against ACA (MBL). The antisera against hSgo2-pT537 (cross-reacting mSgo2-pT521) were produced in rabbits (Operon) with a peptide coupled to keyhole limpet hemocyanin. The antibodies were affinity-purified with immobilized peptides. DNA was stained with $3 \mu \mathrm{g} / \mathrm{mL}$ Hoechst 33342 (Wako). Nocodazole (Sigma), MG132 (Calbiochem), okadaic acid (Wako), hesperadin (provided by Dr. Jan-Michael Peters), ZM447439, and thymidine (Sigma) were added at $330 \mathrm{nM}$, $20 \mu \mathrm{M}, 500 \mathrm{nM}, 50 \mathrm{nM}, 4 \mu \mathrm{M}$, and $2 \mathrm{mM}$, respectively.

\section{Chromosome spreading}

Chromosome spreading was performed as described (Hauf et al. 2003; Yamagishi et al. 2008).

\section{Immunostaining}

Immunostaining was performed as described (Kitajima et al. 2006). Images were captured with DeltaVision and processed with DeltaVision SoftWorx software (Applied Precision).

\section{Live imaging}

HeLa-H2B-EGFP cells were imaged in a Lab-Tek Chambered Coverglass System (Nunc) in phenol red-free Leibovitz's L-15 medium (GIBCO) at $37^{\circ} \mathrm{C}$ under $5 \% \mathrm{CO}_{2}$. Exposures of $0.1 \mathrm{sec}$ were acquired every $5 \mathrm{~min}$ for $36 \mathrm{~h}$ using a $40 \times$ NA 0.75 objective on an Olympus IL-X71 Applied Precision DeltaVision microscope. Point visits were used to follow cells in 10 different fields of view. For analyzing chromosome dynamics in hSgol or hSgo2 mutant cells, EGFP-hSgo1- or hSgo2-expressing cells were transfected with pcDNA5/TO plasmids (Invitrogen) harboring H2A or $\mathrm{H} 2 \mathrm{~B}$ tagged with mCherry at the $\mathrm{C}$ teminus. Endogenous proteins were depleted with RNAi, and images were captured with exposures of $0.05 \mathrm{sec}$ with a $2 \times 2 \mathrm{bin}$ for $36 \mathrm{~h}$.

\section{Preparation of HeLa cell extract and immunoprecipitation}

HeLa cells were synchronized by double-thymidine block and release, and were incubated in the medium containing nocodazole for $15 \mathrm{~h}$ in the presence of MG132 and ZM447439 during the last 3 h. Cells were collected and washed with PBS once, then resuspended in CSK buffer (10 mM PIPES at pH 6.8, $100 \mathrm{mM} \mathrm{NaCl}, 10 \%$ glycerol, $3 \mathrm{mM} \mathrm{MgCl} 2,1 \mathrm{mM}$ EGTA, $1 \mathrm{mM}$ dithiothreitol, 0.25 mM PMSF, $0.1 \mathrm{mM}$ ATP, $1 \mu \mathrm{M}$ okadaic acid, Complete protease inhibitor mixture, PhosStop phosphatase inhibitor mixture [Roche]) containing $1 \mathrm{U} / \mathrm{mL}$ DNase I. After three freeze-thaw cycles, the suspension was centrifuged at $16,100 \mathrm{~g}$ for $15 \mathrm{~min}$. Supernatants were incubated with protein A sepharose beads for $1 \mathrm{~h}$ at $4^{\circ} \mathrm{C}$ to preclear the sample of nonspecific binding to protein A. Precleared supernatants were incubated with anti-hSgo2 antibody- or rabbit IgG-coupled protein A beads for $2 \mathrm{~h}$ at $4^{\circ} \mathrm{C}$, the beads were washed with CSK buffer five times, and the bead-bound proteins were eluted with IP-elution buffer (200 mM glycine at $\mathrm{pH} 2.5,150 \mathrm{mM}$ $\mathrm{NaCl}$ ), neutralized with $1 \mathrm{M}$ Tris ( $\mathrm{pH} 8.0$ ), and boiled for analysis by immunoblot. To detect phosphorylated hSgo2 by immunoblot, cells were lysed with RIPA buffer (50 mM Tris at pH 7.5, $500 \mathrm{mM}$ $\mathrm{NaCl}, 1 \%$ Triton X-100, $10 \mathrm{mM} \mathrm{MgCl}_{2}, 0.1 \%$ SDS).

\section{In vitro kinase and pull-down assays}

GST-fused, His-fused, and MBP-fused proteins were bacterially expressed and purified with Glutathione-sepharose beads (GE), NiNTA beads (Qiagen), and amylose resin (New England Biolabs), respectively. For kination assay, reactions were carried out in $20 \mu \mathrm{L}$ of kinase buffer $\left(50 \mathrm{mM}\right.$ Tris- $\mathrm{HCl}$ at $\mathrm{pH} 7.5,10 \mathrm{mM} \mathrm{MgCl}_{2}, 0.5 \%$ Triton X-100 supplemented with Complete, PhosStop, $1 \mathrm{mM}$ PMSF) in the presence of $10 \mu \mathrm{Ci}$ of ${ }^{32} \mathrm{P}$-labeled ATP. Reaction products were resolved by SDS-PAGE, and the incorporation of ${ }^{32} \mathrm{P}$ was visualized by autoradiography. For the pull-down assay, the purified and bead-bound proteins were phosphorylated individually with His-Aurora B in kination buffer in the presence of $20 \mu \mathrm{M}$ ATP for $30 \mathrm{~min}$ at $30^{\circ} \mathrm{C}$. For mock phosphorylation, ATP was subtracted from the kinase buffer. Reactions were terminated by the addition of $10 \mathrm{mM}$ EDTA (pH 8.0). Phosphorylated proteins were mixed and incubated in binding buffer $(20 \mathrm{mM}$ Tris- $\mathrm{HCl}$ at $\mathrm{pH} 7.5,150 \mathrm{mM}$ $\mathrm{NaCl}, 1 \mathrm{mM}$ EDTA, $10 \%$ glycerol, $0.8 \%$ NP-40, supplemented with Complete, PhosStop, $1 \mathrm{mM}$ PMSF, $5 \mu \mathrm{g} / \mathrm{mL}$ BSA) for $2 \mathrm{~h}$ at $4^{\circ} \mathrm{C}$. The beads were then washed five times with binding buffer. The bead-bound proteins were subjected to SDS-PAGE, transferred onto the Immobilon PVDF membrane (Millipore), and detected by immunoblot.

Immunofluorescence staining of spread chromosome of okadaic acid-induced Meta I spermatocyte

Testes were removed from 18-d-old C57BL/6 male mice, detunicated, treated with collagenase, and filtered. The isolated spermatocytes were cultured in DMEM/ $10 \%$ fetal bovine serum and induced to undergo metapahase I by the addition of $5 \mu \mathrm{M}$ okadaic acid for $6 \mathrm{~h}$ (Wiltshire et al. 1995). Okadaic acid was washed out and then cultured in the presence or absence of $4 \mu \mathrm{M}$ ZM447439 for another $60 \mathrm{~min}$. For the preparation of spread chromosomes, cells were fixed in $1 \%$ PFA with $0.1 \%$ Triton X-100 (Peters et al. 1997).

\section{Acknowledgments}

We thank Silke Hauf for critically reading the manuscript. We thank Yukiko Gotoh, Toru Hirora, Patrick Meraldi, Paul D. 
Andrew, Jason Swedlow, Jan-Michael Peters, and Atsushi Enomoto for reagents. We also thank all of the members of our laboratory for their valuable support and discussion. This work was supported in part by JSPS Research Fellowship (to T.Y. and T.H.) and Grant-in-Aid for Young Scientists (to K.I.), the Global COE Program (Integrative Life Science Based on the Study of Biosignaling Mechanisms), MEXT-Japan, and a Grantin-Aid for Specially Promoted Research from the MEXT-Japan (to Y.W.).

\section{References}

Andrews PD, Ovechkina Y, Morrice N, Wagenbach M, Duncan K, Wordeman L, Swedlow JR. 2004. Aurora B regulates MCAK at the mitotic centromere. Dev Cell 6: 253-268.

Cheeseman IM, Desai A. 2008. Molecular architecture of the kinetochore-microtubule interface. Nat Rev Mol Cell Biol 9: 33-46.

Cheeseman IM, Chappie JS, Wilson-Kubalek EM, Desai A. 2006. The conserved KMN network constitutes the core microtubule-binding site of the kinetochore. Cell 127: 983-997.

Ciferri C, Pasqualato S, Screpanti E, Varetti G, Santaguida S, Dos Reis G, Maiolica A, Polka J, De Luca JG, De Wulf P, et al. 2008. Implications for kinetochore-microtubule attachment from the structure of an engineered Ndc80 complex. Cell 133: 427-439.

Dai J, Sullivan BA, Higgins JMG. 2006. Regulation of mitotic chromosome cohesion by haspin and Aurora B. Dev Cell 11: 741-750.

DeLuca JG, Gall WE, Ciferri C, Cimini D, Musacchio A, Salmon ED. 2006. Kinetochore microtubule dynamics and attachment stability are regulated by Hec1. Cell 127: 969-982.

Ditchfield C, Johnson VL, Tighe A, Ellston R, Haworth C, Johnson T, Mortlock A, Keen N, Taylor SS. 2003. Aurora B couples chromosome alignment with anaphase by targeting BubR1, Mad2, and Cenp-E to kinetochores. J Cell Biol 161: 267-280.

Gomez R, Valdeolmillos A, Parra MT, Viera A, Carreiro C, Roncal F, Rufas JS, Barbero JL, Suja JA. 2007. Mammalian SGO2 appears at the inner centromere domain and redistributes depending on tension across centromeres during meiosis II and mitosis. EMBO Rep 8: 173-180.

Guimaraes GJ, Dong Y, McEwen BF, Deluca JG. 2008. Kinetochore-microtubule attachment relies on the disordered N-terminal tail domain of Hec1. Curr Biol 18: 1778-1784.

Hauf S, Cole RW, LaTerra S, Zimmer C, Schnapp G, Walter R, Heckel A, van Meel J, Rieder CL, Peters J-M. 2003. The small molecule Hesperadin reveals a role for Aurora B in correcting kinetochore-microtubule attachment and in maintaining the spindle assembly checkpoint. J Cell Biol 161: 281294.

Hauf S, Roitinger E, Koch B, Dittrich CM, Mechtler K, Peters J-M. 2005. Dissociation of cohesin from chromosome arms and loss of arm cohesion during early mitosis depends on phosphorylation of SA2. PLoS Biol 3: e69. doi: 10.1371/ journal.pbio.0030069.

Hirano T. 2000. Chromosome cohesion, condensation, and separation. Annu Rev Biochem 69: 115-144.

Huang H, Feng J, Famulski J, Rattner JB, Liu ST, Kao GD, Muschel R, Chan GK, Yen TJ. 2007. Tripin/hSgo2 recruits MCAK to the inner centromere to correct defective kinetochore attachments. J Cell Biol 177: 413-424.

Ishiguro T, Tanaka K, Sakuno T, Watanabe Y. 2010. ShugoshinPP2A counteracts casein-kinase-1-dependent cleavage of Rec8 by separase. Nat Cell Biol 12: 500-506.

Johnson VL, Scott MI, Holt SV, Hussein D, Taylor SS. 2004. Bubl is required for kinetochore localization of BubRl,
Cenp-E, Cenp-F and Mad2, and chromosome congression. J Cell Sci 117: 1577-1589.

Katis VL, Lipp JJ, Imre R, Bogdanova A, Okaz E, Habermann B, Mechtler K, Nasmyth K, Zachariae W. 2010. Rec8 phosphorylation by casein kinase 1 and Cdc7-Dbf4 kinase regulates cohesin cleavage by separase during meiosis. Dev Cell 18: 397-409.

Kawashima SA, Tsukahara T, Langegger M, Hauf S, Kitajima TS, Watanabe Y. 2007. Shugoshin enables tension-generating attachment of kinetochores by loading Aurora to centromeres. Genes Dev 21: 420-435.

Kawashima SA, Yamagishi Y, Honda T, Ishiguro K-I, Watanabe Y. 2010. Phosphorylation of H2A by Bub1 prevents chromosomal instability through localizing shugoshin. Science 327:172-177.

Kitajima TS, Hauf S, Ohsugi M, Yamamoto T, Watanabe Y. 2005. Human Bub1 defines the persistent cohesion site along the mitotic chromosome by affecting shugoshin localization. Curr Biol 15: 353-359.

Kitajima TS, Sakuno T, Ishiguro K, Iemura S, Natsume T, Kawashima SA, Watanabe Y. 2006. Shugoshin collaborates with protein phosphatase $2 \mathrm{~A}$ to protect cohesin. Nature 441: 46-52.

Kline-Smith SL, Khodjakov A, Hergert P, Walczak CE. 2004. Depletion of centromeric MCAK leads to chromosome congression and segregation defects due to improper kinetochore attachments. Mol Biol Cell 15: 1146-1159.

Lan W, Zhang X, Kline-Smith SL, Rosasco SE, Barrett-Wilt GA, Shabanowitz J, Hunt DF, Walczak CE, Stukenberg PT. 2004. Aurora B phosphorylates centromeric MCAK and regulates its localization and microtubule depolymerization activity. Curr Biol 14: 273-286.

Lee JY, Hayashi-Hagihara A, Orr-Weaver TL. 2005. Roles and regulation of the Drosophila centromere cohesion protein MEI-S332 family. Philos Trans $R$ Soc Lond B Biol Sci 360: $543-552$.

Lee J, Kitajima TS, Tanno Y, Yoshida K, Morita T, Miyano T, Miyake M, Watanabe Y. 2008. Unified mode of centromeric protection by shugoshin in mammalian oocytes and somatic cells. Nat Cell Biol 10: 42-52.

Liu D, Vader G, Vromans MJ, Lampson MA, Lens SM. 2009. Sensing chromosome bi-orientation by spatial separation of aurora B kinase from kinetochore substrates. Science 323: 1350-1353.

Llano E, Gomez R, Gutierrez-Caballero C, Herran Y, SanchezMartin M, Vazquez-Quinones L, Hernandez T, de Alava E, Cuadrado A, Barbero JL, et al. 2008. Shugoshin-2 is essential for the completion of meiosis but not for mitotic cell division in mice. Genes Dev 22: 2400-2413.

Losada A, Hirano M, Hirano T. 2002. Cohesin release is required for sister chromatid resolution, but not for condensin-mediated compaction, at the onset of mitosis. Genes Dev 16: 3004-3016.

McGuinness BE, Hirota T, Kudo NR, Peters J-M, Nasmyth K. 2005. Shugoshin prevents dissociation of cohesin from centromeres during mitosis in vertebrate cells. PLOS Biol 3: e86. doi: 10.1371/journal.pbio.0030086.

Miller SA, Johnson ML, Stukenberg PT. 2008. Kinetochore attachments require an interaction between unstructured tails on microtubules and Ndc80(Hec1). Curr Biol 18: 1785-1791.

Nasmyth K, Peters JM, Uhlmann F. 2000. Splitting the chromosome: Cutting the ties that bind sister chromatids. Science 288: 1379-1385.

Ohi R, Burbank K, Liu Q, Mitchison TJ. 2007. Nonredundant functions of Kinesin-13s during meiotic spindle assembly. Curr Biol 17: 953-959. 
Parra MT, Gómez R, Viera A, Page J, Calvente A, Wordeman L, Rufas JS, Suja JA. 2006. A perikinetochoric ring defined by the microtubule-depolymerising kinesin MCAK as a new centromere domain in meiosis. PLoS Genet 2:798-810.

Peters AH, Plug AW, van Vugt MJ, de Boer P. 1997. A drying-down technique for the spreading of mammalian meiocytes from the male and female germline. Chromosome Res 5: 66-68.

Peters JM, Tedeschi A, Schmitz J. 2008. The cohesin complex and its roles in chromosome biology. Genes Dev 22: 30893114.

Resnick TD, Satinover DL, MacIsaac F, Stukenberg PT, Earnshaw WC, Orr-Weaver TL, Carmena M. 2006. INCENP and Aurora B promote meiotic sister chromatid cohesion through localization of the Shugoshin MEI-S332 in Drosophila. Dev Cell 11: $57-68$.

Riedel CG, Katis VL, Katou Y, Mori S, Itoh T, Helmhart W, Galova M, Petronczki M, Gregan J, Cetin B, et al. 2006. Protein phosphatase 2A protects centromeric sister chromatid cohesion during meiosis I. Nature 441: 53-61.

Salic A, Waters JC, Mitchison TJ. 2004. Vertebrate shugoshin links sister centromere cohesion and kinetochore microtubule stability in mitosis. Cell 118: 567-578.

Tanaka TU. 2008. Bi-orienting chromosomes: Acrobatics on the mitotic spindle. Chromosoma 117: 521-533.

Tanaka TU, Rachidi N, Janke C, Pereira G, Galova M, Schiebel E, Stark MJ, Nasmyth K. 2002. Evidence that the Ipl1-Sli15 (Aurora kinase-INCENP) complex promotes chromosome bi-orientation by altering kinetochore-spindle pole connections. Cell 108: 317-329.

Tang Z, Shu H, Qi W, Mahmood NA, Mumby MC, Yu H. 2006. PP2A is required for centromeric localization of Sgol and proper chromosome segregation. Dev Cell 10: 575-585.

Tsukahara T, Tanno Y, Watanabe Y. 2010. Phosphorylation of the CPC by Cdk1 promotes chromosome bi-orientation. Nature doi: 10.1038/nature09390.

Watanabe Y. 2005. Shugoshin: Guardian spirit at the centromere. Curr Opin Cell Biol 17: 590-595.

Welburn JP, Vleugel M, Liu D, Yates JR III, Lampson MA, Fukagawa T, Cheeseman IM. 2010. Aurora B phosphorylates spatially distinct targets to differentially regulate the kinetochore-microtubule interface. Mol Cell 38: 383-392.

Wiltshire T, Park C, Caldwell KA, Handel MA. 1995. Induced premature G2/M-phase transition in pachytene spermatocytes includes events unique to meiosis. Dev Biol 169: 557567.

Xu Z, Cetin B, Anger M, Cho US, Helmhart W, Nasmyth K, Xu W. 2009. Structure and function of the PP2A-shugoshin interaction. Mol Cell 35: 426-441.

Yamagishi Y, Sakuno T, Shimura M, Watanabe Y. 2008. Heterochromatin links to centromeric protection by recruiting shugoshin. Nature 455: 251-255.

Zhang X, Lan W, Ems-McClung SC, Stukenberg PT, Walczak CE. 2007. Aurora B phosphorylates multiple sites on mitotic centromere-associated kinesin to spatially and temporally regulate its function. Mol Biol Cell 18: 3264-3276. 


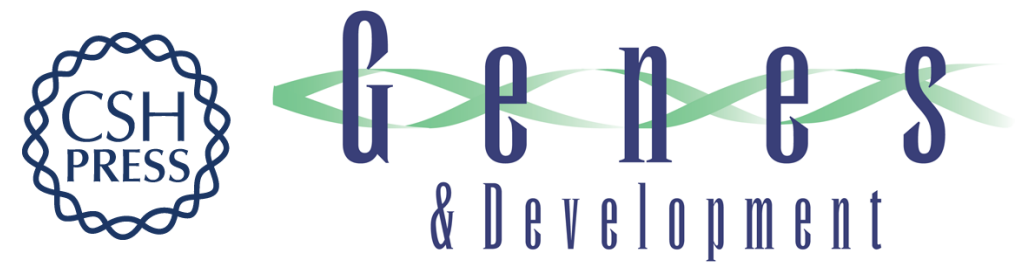

\section{Phosphorylation of mammalian Sgo2 by Aurora B recruits PP2A and MCAK to centromeres}

Yuji Tanno, Tomoya S. Kitajima, Takashi Honda, et al.

Genes Dev. 2010, 24:

Access the most recent version at doi:10.1101/gad.1945310

Supplemental http://genesdev.cshlp.org/content/suppl/2010/09/27/24.19.2169.DC1
Material

References This article cites 46 articles, 13 of which can be accessed free at: http://genesdev.cshlp.org/content/24/19/2169.full.html\#ref-list-1

License Freely available online through the Genes \& Development Open Access option.

Email Alerting Receive free email alerts when new articles cite this article - sign up in the box at the top Service right corner of the article or click here.

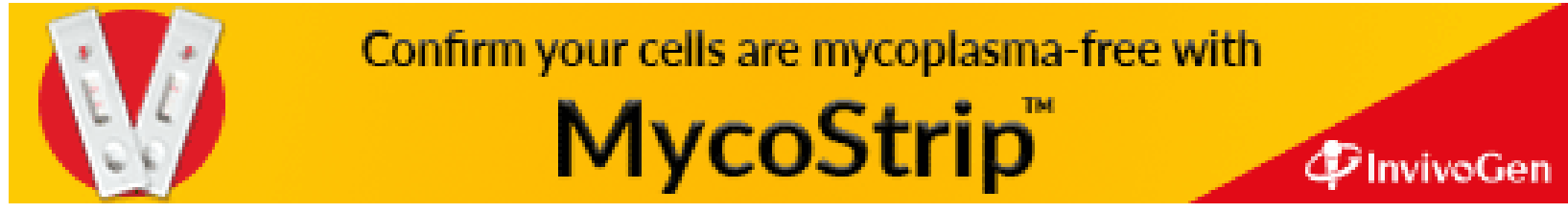

